International Journal of Social Science and Economic Research

ISSN: $2455-8834$

Volume: 05, Issue: 07 "July 2020"

\title{
MARK IT: ANALYZING WASTE MANAGEMENT SYSTEMS ACROSS FOOD RETAILERS IN INDIA
}

\author{
Anya Goyal \\ Step By Step School, Noida \\ DOI: 10.46609/IJSSER.2020.v05i07.028 URL: https://doi.org/10.46609/IJSSER.2020.v05i07.028
}

\begin{abstract}
India has experienced high rates of economic development in the past few decades that have made it one of the leading food producers in the world. However, India continues to have the highest number of malnourished people in the world, with malnourishment and food insecurity impacting many sections of the Indian population. This paper has explored the impacts of this nutrition crisis in India and found that it not only hampers the health and economic productivity of individuals but hampers the economic development of the country in the long run. There has been a rapid increase in the number of supermarkets in urban India, which have given rise to supply and consumption behavior that leads to high levels of wastage of food that continues to be edible. This paper has explored the extent of food wastage during retail in India and its impact on food security, environmental degradation, and economic productivity. It has been found that the prevention of food wastage at the retail level is one of the key aspects in solving the nutrition crisis in India, despite it being ignored in subsequent state policies. Lastly, this paper has sought to provide policy recommendations surrounding the development of cold storage systems and the creation of partnerships with non-profit initiatives that seek to enable supermarkets and local governments to redirect discarded food to communities that suffer the most from acute malnutrition.
\end{abstract}

Keywords: Food retailers, Economic development, Environmental degradation, Food production

\section{INTRODUCTION}

India faces acute levels of food shortage every year which has adverse impacts on the poorest and most marginalized sections of Indian society. India is ranked 102nd out of 117 countries in the Global Hunger Index 2019 (Press Trust of India, 2019). Every one out of nine citizens in India faces food shortages on a regular basis (Nigam \& Sharma, 2017). The unavailability of food which causes problems ranging from undernourishment to child stunting is less because of 


\section{International Journal of Social Science and Economic Research}

ISSN: $2455-8834$

Volume: 05, Issue: 07 "July 2020"

low food production and more because of the wastage of food which occurs due to the absence of efficient food management systems throughout the supply chain. This also alludes to the growth of economic inequality in India that has accompanied economic development and the increase in GDP. Every year in India, about $18 \%$ of fruits and vegetables are wasted due to the lack of post-harvest storage infrastructure. Research conducted by the United Nations' Food and Agriculture Organisation found that, annually, $40 \%$ of India's fresh fruits and vegetables which are worth $\$ 8.3$ billion perish before reaching consumers (Sivraman, 2016). The nutrition crisis in India is therefore fueled by the mismanagement of produce, the absence of storage facilities and the lack of initiative on the part of grocery stores and other retailers to channelize unsold food products to productive channels to facilitate consumption and avoid wastage. It is imperative to tackle the problem of food wastage to solve the nutrition crisis in India.

Food wastage is defined as the processes of discarding raw, processed or cooked food materials at any stage in the supply chain or during the process of consumption (Srinivas \& Dongre, 2018). Even though some parts of food wastage are unavoidable- primarily because of the lack of demand for commodities that are considered to be inedible, avoidable food wastage has been a problem that India has increasingly faced since the economic reforms of 1991. Consumers tend to be reluctant in purchasing commodities whose shelves are only partly filled or almost empty. The fear of being penalized by customers due to the absence of $100 \%$ shelf availability often drives retail outlets (most of whom are owned by large scale corporations) to keep the excess product on hand or ensure it's available at a short notice. This fear encourages overproduction in primary production, processing, and manufacturing. The inherent stigma against 'perfect' food commodities in the eyes of Indian consumers also leads to the rejection and wastage of edible nutritious food. Produce if often bruised or spoiled by untrained or inattentive staff which renders it 'unsellable'. Produce that is not sold is typically sent to landfill and discarded as waste. Retailers in India seldom take the onus of connecting with food rescue organizations (Fernandes, 2019).

The impacts of malnutrition are worst faced by socio-economically disadvantaged communities. Food security continues to be a reality for a significant number of Indian families that exist below the poverty line (Gulati, et. al., 2012). Malnutrition, fueled by the wastage of food not only adds to the increase in the risk of contracting diseases including anemia and tuberculosis, reduces the economic productivity of individuals, increases the mortality rate of children at the individual level but also leads to hampered economic development and increased public expenditure at the societal level. Public authorities and governments in India have ignored the aspect of food wastage whilst formulating policies aimed at tackling the malnutrition crisis in India, which has hindered the effectiveness of legislation such as the National Food Security Act, 2013. 
International Journal of Social Science and Economic Research

ISSN: $2455-8834$

Volume: 05, Issue: 07 "July 2020"

\section{BACKGROUND}

According to a preparatory study conducted by the European Commission Directorate, the manufacturing industry is responsible for $39 \%$ of the food wastage in the European Union and the retail and wholesale sector is responsible for $19 \%$ of the wastage (Monier, et. al., 2010). Beaver explored the patterns of food wastage in the United Kingdom and concluded that perishable products are the major contributors towards the food waste and that wastage during the time of retail is often a product of perception. The study claims that the behaviors and attitudes of customers surrounding the appearance and package of food often determine consumption decisions (Beaver, 2018). The introduction of artificial standards and grades of food which lead to the classification of certain packages of food as 'undesirable' despite them being edible is considered to be a major barrier in attempts to reduce the wastage of food. Customers often conflate government-mandated standards of safety in food and artificial markers that seek to create product differentiation which leads to the drastic decrease in demand for food and its subsequent wastage. Even though these trends are more common in Europe and the United States, research by Srinivas and Dongre shows that the rise in disposable income and easy accessibility to food for the urban Indian middle class has gradually given rise to food wastage at the retail level in India (Srinivas \& Dongre, 2018).

India's ability to provide food to the most needy is largely curbed by the lack of food storage facilities. Cold Storage facilities are highly underdeveloped and are inaccessible to most primary producers. Only $2 \%$ of the primary produce of India is held or transported using cold storage facilities. The development of these facilities has been key to filling gaps between supply and demand in western nations. $85 \%$ of the primary produce of the United States is kept in cold storage before it reaches the final consumers (Sivaraman, 2016). Research suggests that restrictions and barriers imposed by the government such as poor roads, bureaucratic corruption, the lack of awareness around handling perishable products and the lack of electrical power supplies that are critical for storing food over long periods of time have contributed to the lack of access of producers and middlemen to storage and delivery systems. (Sivaraman, 2016). Whilst states like Punjab and Haryana produce surpluses in agriculture, states like Jharkhand and Bihar face acute food shortages. The development of storage facilities has an impact on multiple industries and is key in making many essential foods including fruits, vegetables, milk, fish, meat, cereals, and pulses available at cheaper prices.

\section{DISCUSSION}

The Global Hunger Index places India at the 67th position out of 80 nations in the survey. According to this survey, the hunger and nutrition situation in India is worse than in countries such as North Korea and Sudan. India's high and increasingly growing population puts a high 


\section{International Journal of Social Science and Economic Research}

ISSN: $2455-8834$

Volume: 05, Issue: 07 "July 2020"

amount of pressure on the food resources in the country. $25 \%$ of all the hungry in the world live in India. Despite policy interventions, the percentage of hungry individuals in India has only increased since 1991 due to a sharp increase in the population. The shifting consumption patterns, especially amongst the Indian middle-class has also contributed to food shortages. The growth of consumerism and private industry has made high-quality food available to Indian households. Even though the availability of better quality commodities is considered to be an indicator of increasing standard of living, the perception of 'quality', which is often artificially manufactured by large scale food manufacturers and vendors and its subsequent impact on consumption and sales patterns have given rise to higher levels of wastage. This phenomenon is usually observed in developing countries, where large amounts of food is wasted because they do not adhere to commercial standards, which are often not based on nutrition- but on aesthetics (Nigam \& Sharma, 2017). The food which does not make it to the shelves of grocery stores because its inability to adhere to artificially set standards seldom makes its way to impoverished citizens. Most organizations that are a part of the supply chain of food turn a blind eye to recycling and lack processes and mechanisms used to redirect food that does not meet commercial standards to communities that suffer from high levels of poverty and malnutrition.

The state's response to the nutrition crisis has also been ignorant of the problem of food wastage and has only focused on increasing the supply of food. The National Food Security Act, 2013 mainly focuses on implementing a Targeted Public Distribution Network of identifying economically weaker households and supplying them with basic food necessities at a subsidized rate. It also allows for maternity benefits, the midday meal scheme and a grievance redressal system. However, the implementation of this Act has been ineffective at a national level because of implementation gaps, corruption and the dearth of resources at the state and local levels. Even though there is much scope of reform in the Targeted Public Distribution Network and the Midday Meal Scheme, the intensity of malnutrition in India demands supplemental solutions to the food crisis beyond government delivery systems, and research suggests that reducing the wastage of food, especially at the retail level is key to making food available to the most vulnerable sections of society (Balarajan \& Reich, 2016).

Malnutrition has adversely affected the physical and mental health of individuals, the standard of living, economic productivity, social mobility and the potential for economic development at the macro level. In India $44 \%$ of children under the age of 5 are underweight. $72 \%$ of infants and $52 \%$ of adults have some sort of nutrition deficiency. Research has conclusively shown that malnutrition during pregnancy causes the child to have increased risk of future diseases, physical retardation, and reduced cognitive abilities (Verma, 2012). Malnutrition also increases the risk of contracting infectious diseases such as pneumonia and tuberculosis, which lead to a higher mortality rate. The lack of energy and an increased risk of morbidity leads to lower economic 


\section{International Journal of Social Science and Economic Research}

ISSN: $2455-8834$

Volume: 05, Issue: 07 "July 2020"

productivity. This causes the economically deprived sections of society to be trapped in a vicious circle of under-nutrition. The absence of access to healthy food causes people to be less productive economically which in turn severely reduces their ability to access healthy food, even in a mixed economy like India (WHO, 2012). Malnutrition also leads to social harm at a national level and adds to inefficiency in the society and industry, especially in India where labor is a major input factor for economic production. A malnourished workforce implies a significant loss in the potential for economic productivity and development (The World Bank, 2012). Patterns of food wastage are also linked to environmental degradation. When food is wasted by communities without fulfilling the demand for food amongst all citizens, the overproduction of food occurs as a necessary consequence. Therefore, the level of wastage of food is directly related to the level of food production. This food production often occurs through unsustainable methods such as Slash and Burn Cultivation, the use of harmful pesticides and fertilizers in developing countries like India. These methods are associated with the reduction in long term productivity of soil, water pollution due to runoff, and threats to wildlife.

The absence of waste management systems at the retail level implies a higher economic burden for the state and the most vulnerable members of society. When overproduced food is not allocated to those consumers who have the highest unsatisfied demand, the prices tend to go up and the entire market ends up spending more on food. The burden of higher costs is felt by the poor, who cannot access quality food and often suffer from malnutrition and associated diseases. The provision of food to the poor also accounts for significant levels of government expenditure. The expenditure incurred by the Indian government under the National food security act amounts to Rs 150,000 crores annually- which is expected to be reduced by the reduction of food wastage (Dash, 2014)

\section{CONCLUSION}

India has achieved significant rates of economic growth in the past three decades. This is primarily due to the increasing liberalization and privatization of the Indian economy. Even though these policies have accelerated economic growth rates, that has come at the cost of increasing the economic gap that exists between the rich and the poor. This growth of private enterprises in India has been fueled by high rates of private investment. Most of the retail food supply in India is presently under the control of a few conglomerates which have enjoyed high profits over the past decade. However, changes in consumption and supply patterns due to the growth of modern-day supermarkets have contributed significantly to food wastage in India, which already suffers from high rates of poverty and malnutrition. Increased economic returns to the large-scale business essentially come at the cost of the food security of the poorest communities of India. There is a need to introduce changes in the process through which food 


\section{International Journal of Social Science and Economic Research}

ISSN: $2455-8834$

Volume: 05, Issue: 07 "July 2020"

reaches from the point of production till it is finally consumed in order to make the most of it and reduce wastage of food and malnutrition.

The government has ignored wastage as a contributor to food shortages whilst drafting legislation aimed at solving food security problems. There is a need for the government to impose penalties against large-scale chain retailers for wasting food in an attempt to deter them from doing so. Governments should also prevent food manufacturers from using artificially created standards that mislead consumers into thinking that certain foods are 'inedible'. Public authorities should also launch awareness campaigns that seek to link food wastage with the malnutrition crisis that plagues many communities in India in order to nudge consumers towards changing their consumption habits, holding retailers accountable and reducing the domestic wastage of food. Consumer boards and forums must also educate consumers to enable them to differentiate between state-authorized and artificially imposed food standards to reduce unsustainable consumption practices. The development of food storage and management systems, which are in dearth in India by manufacturers, retailers, and wholesalers is instrumental in reducing the wastage of food at all levels of the supply chain. Given that India produces enough food to meet the demand, the shortcomings of this sector lies in its inability to fill the gaps that exist between the demand and supply of food. The creation and maintenance of a robust network of cold storages and transport infrastructure are required to keep the farm produce remunerative, moderate retail food inflation and maintain food security. Recently, India has witnessed the growth of many Non-Governmental Organizations and not-for-profit initiatives that work to make food that is discarded by retailers and supermarkets but continues to be edible available to those who struggle to maintain adequate levels of nutrition for themselves and their families. Organizations such as the Robin Hood Army have been instrumental in providing food securities to many families in the communities where they operate. However, they often lack the resources to undertake large scale operations.

Redirecting food that has been discarded by grocery stores and supermarkets to communities in need of that food by setting up a system of storage and distribution of food through the combined efforts of local-level governments, businesses and consumers can be instrumental in solving the food security and malnutrition crisis that affects some of the most vulnerable sections of the Indian population.

\section{BIBLIOGRAPHY}

Balarajan, Y., Reich, M. R. (2016). Political economy of child nutrition policy: A qualitative study of India's Integrated Child Development Services (ICDS) scheme. Food Policy. Accessed on 13th April 2020 
International Journal of Social Science and Economic Research

ISSN: 2455-8834

Volume: 05, Issue: 07 "July 2020"

Beaver, M. (2018). Managing Food Wastage in Consumer Households. Accessed on 13th April 2020

Dash (D.K.). Food security deadline for states expires without extension. Times of India, 8th October, 2014

Fernandes, K. (2019). CSR: Food Wastage in Retail. The CSR Jornal, Accessed on 12th April 2020

Gulati, A., Ganesh-Kumar, A., Shreedhar, G., \& Nandakumar, T. (2012). Agriculture and malnutrition in India. Food And Nutrition Bulletin, Accessed on 13th April 2020

Monier, V., Shailendra, M., Escalon V., O'Connor, C. Gibon, T. Anderson, G. Hortense, M. Reisinger, H. (2010) . Preparatory study on Food Waste across EU27. European Commission (DG ENV) Directorate C- Industry. 2010. Final Report. Accessed on 10th April 2020

Nigam, R. \& Sharma, S. (2017). Food Waste Management. Amity Journal of Energy \& Environmental Sciences. Accessed on 11th April 2020

Press Trust of India. The Global Hunger Index 2019: India ranked lower than Nepal, Pakistan, and Bangladesh. The Hindu, 17th October 2019

Sivaraman, M. (2016). Government's Role in India's Ailing Cold Storage Sector. Center for Public Policy Research. Accessed on 10th April 2020

Srinivas, K. \& Donger, R. (2018). A Study of Generation of Food Waste And Awareness Regarding Wastage Amongst Indian Households. International Journal for Trends in Scientific Research and Development. Accessed on 12th April 2020

The World Bank. (2012). A Call for Reform and Action. Accessed on 10th April 2020

Verma, S. Superpower? 230 million Indians go hungry daily. The Times of India, 15th January 2012

World Health Organization. (2012). Turning the Tide on Malnutrition. Accessed on 10th April 2020 